\title{
Micro Structural Properties of Ternary Blended Concrete
}

\author{
Gomasa Ramesh
}

\begin{abstract}
The sum of $\mathrm{CO}_{2}$ that has been released into the atmosphere is roughly equal to the amount of cement produced. Cement manufacturing now consumes many natural resources and cement substitute materials in the analysis of Micro Structural Properties of Ternary Blended Concrete. The mixed proportion in this analysis is made of M30 Concrete. The cement is substituted with a mixture of two materials in amounts ranging from $10 \%$ to $50 \%$. For the mix of materials, Fly Ash is kept constant. The specimen is a 150mmx150mmx150mm cube, and the concrete is cast in a $150 \mathrm{mmx} 300 \mathrm{~mm}$ cylinder. The cast specimens are held for 28 days to cure. Compressive and split tensile strength tests are used to achieve the results. The combination at $10 \%$, at $20 \%$, at $20 \%$, and $20 \%$ produced better strength results in all proportions from $10 \%$ to $50 \%$. Besides, scanning electron microscopy techniques were used to understand better phase changes and the formation of microstructures to maturing the combination of materials at various percentages. SEM was used to evaluate the microstructure of the concrete for five different varieties, which helps with solid growth. With the highest compressive strength gained among all the mixes from $10 \%$ to $50 \%$ with combinations for M30 grade of concrete at 28 days, significant innovative information on particle shape and microstructure was observed. Via SEM study, a good correlation of this Microscopical quantitative knowledge and material properties is also presented.

Keyword: Ternary Blended Concrete, Micro Structure Properties, Properties of Materials, Applications, Silica fume, High strength concrete, Nano Alumina.
\end{abstract}

\section{INTRODUCTION}

$\mathrm{H}$ umankind invented concrete, which is a heterogeneous substance. It is the most commonly used building material today, with an annual global production of over 4.5 billion metric tons. As a primary building material, concrete is used in a wide range of construction projects, including hydraulic systems, highway buildings, etc. This material must have the following properties: resilience, toughness, impermeability, fire resistance, and abrasion resistance. To achieve higher strength, cement is substituted with cementitious materials. Concrete is traditionally made with ordinary Portland Cement as the primary binder. Furthermore, the amount of energy needed to manufacture Ordinary Portland Cement is second only to steel and aluminum in terms of energy consumption. Despite its flexibility, cement concrete has many disadvantages, including poor tensile strength, permeability to liquids resulting from insulation.

Manuscript received on 11 May 2021 | Revised Manuscript received on 13 May 2021 | Manuscript Accepted on 15 November 2021 | Manuscript published on 30 November 2021. * Correspondence Author

Gomasa Ramesh*, Department of Civil and Structural Engineering Vaagdevi College of Engineering, Warangal, 506005, Telangana, India EMail:rameshgomasa1@gmail.com

(C) The Authors. Published by Lattice Science Publication (LSP). This is an open access article under the CC-BY-NC-ND license (http://creativecommons.org/licenses/by-nc-nd/4.0/)
The current emphasis is on finding waste materials or by-products from manufacturing processes that can be used in concrete without losing its strength. In a country like India, where infrastructure projects such as significant irrigation, road, and construction projects are either being built or are nearing completion of their planning and design stages, using waste material in cement concrete would not only minimize greenhouse gas emissions. Still, it will also be a sustainable way of managing waste. A variety of studies are being conducted in India and worldwide to determine the effect of using these Pozzolanic materials as cement substitutes, and the results are promising. The properties of the materials in concrete, the proportion of the mix, and combining mineral and chemical admixtures are critical in achieving the necessary strength. Many industrial constructions waste with pozzolanic activity or a chemical composition similar to cement are also being tried as supplementary cementitious materials and the mineral admixtures listed above. The researchers have tested several works involving ternary blended concrete. The explanation for this is the improved concrete output as a result of the joint operation. The presence of these pozzolanic materials causes fresh concrete to shrink and the density of the transition zone to increase. Three variations of cementitious materials are used to improve the strength of the structure. Many state highway authorities have adopted cementitious materials in concrete bridge decks to increase longevity. Wide variations exist between concrete raw materials, affecting the concrete's short-term properties and long-term durability. As a result, concrete mixtures can't be fully optimized unless local materials are directly texturized, and the concrete produced with those materials is evaluated against local performance demands. Since most cement plants in India are still relatively new, they use cutting-edge technologies that are both energy and resource-efficient. Unless there is a shift in cement production technology or cement composition, emissions are expected to rise in lockstep with cement production. Supplementary cementitious materials provide the most promising means of reducing these emissions. However, some scholars have challenged the advantages of these cementitious materials, which are considered less reactive concrete. When used in various amounts with other cementitious materials, it has been carried out.

\section{APPLICATIONS}

- Combinations of cementitious materials for structure are made in this part of the crisis area of applications, which may be helpful to use in practice. The study's findings are based on a literature review of the most exciting applications.

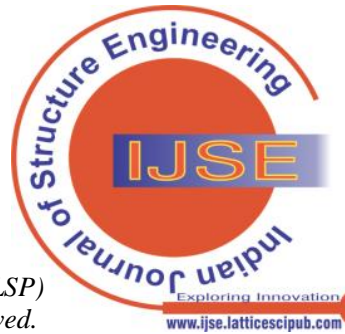


- Construction in general (residential, commercial, industrial)

- Concrete of high efficiency

- Masonry and masonry units are two types of masonry.

- Precast Concrete is used for paving, and mass concrete is used for mass Concrete.

\section{OBJECTIVES AND GOALS}

Cementitious materials and Rice Husk Ash are partly substituted with a cement mixture, which binds the coarse and fine aggregates and forms the concrete. Ternary concrete is made using standard concrete technology methods. Aggregates occupy between 75-80 percent of the mass in concrete, similar to OPC concrete.

- The following are the study's goals:

- To create Ternary Blended Concrete, a mixed

- To assess the compressive and break strength of concrete of the M30 grade.

- To research crystal structure to classify the crystalline phases present in the substance and expose the chemical composition using $x$-ray diffraction analysis.

\section{METHODOLOGY}

\section{Materials Used}

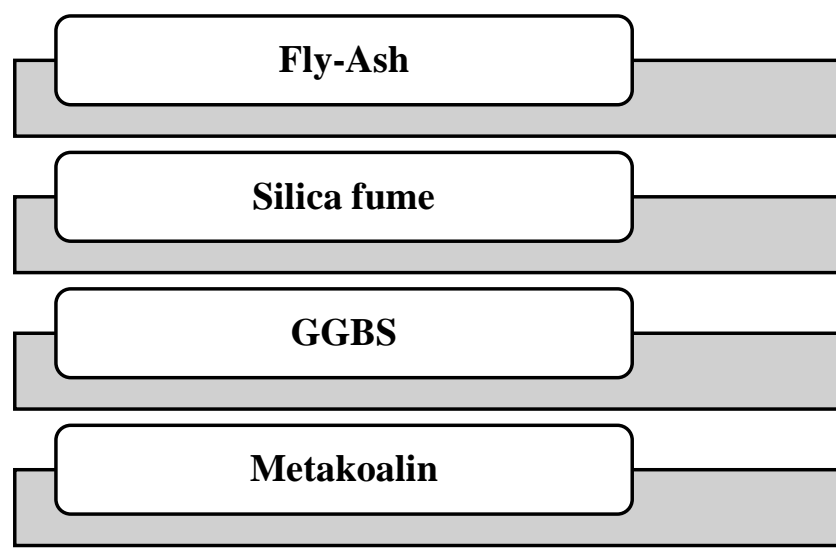

Fly Ash

- $\quad$ Fly ash has several advantages in concrete.

- The following are some of the benefits discovered by various investigators in India:

- Pozzolanic action is superior.

- Reduce the amount of water used.

- Workability has improved.

- Water-reducing admixtures have a more efficient action.

- Increases the amount of time it takes to set but stays within limits.

- The heat of hydration is reduced.

- Drying shrinkage is reduced.

- The ultimate compressive power, tensile strength, and bond strength are all higher.

- $\quad$ Fly ash has a variety of applications. proportion must be completed.

- As a wood replacement, fly ash is used.

- It is used in the production of Portland cement.

- They are typically used in the construction of embankments.

- As a soil stabilization material, it is used.

- In the production of flowable fill, fly ash is also used as a part.

- To fill voids in asphalt road laying, it is used as a filler mineral.

- Alkali reactive aggregates are used.

\section{Silica Fume}

- Advantages of Silica in Concrete

- As silica is applied to ordinary Portland cement, it improves the following properties:

- Bond Enhancement

- Heat hydration is reduced.

- Alkali aggregate reaction is reduced.

- Compressive strength is increased.

- Permeability has been reduced.

- Reduces bleeding to a minimum.

- Improves concrete's freeze/thaw resistance.

Ggbs

- Lower heat hydration is improved.

- As compared to ordinary concrete, it has a higher resistance to sulphate and chloride attack.

- Reduces the amount of cement used in concrete manufacturing.

- More effectively protect the steel reinforcement.

- Increase the resistance to chloride infiltration.

- GGBS may be used for a variety of purposes.

- The chance of harmful inter reactions, such as ASR, is eliminated.

- Chloride resistance is high, which reduces the risk of reinforcement corrosion.

- Sulphate and other chemicals have a high resistance to attack.

- There are significant environmental advantages.

\section{Metakoalin}

- It is a type of amino acid, and It has an average of 1 to 2 microns and is white, affecting the final product's colour.

- Metakaolin's Benefits in Concrete:

- Concrete's strength and endurance improve.

- The concrete's initial setting time is sped up.

- Concrete's compressive strength improves.

- The structure's cross-section can be safely reduced.

- $\quad$ Reduces concrete shrinkage.

- Eco-friendly because it reduces $\mathrm{CO}_{2}$ emissions.

- Reduces hydration heat, which causes shrinkage cracking.






\section{Metakaolin's Applications}

- By converting fine particles into discontinuous pores, it decreases the size of pores in cement paste.

- It improves the compressive and flexural strength of the material.

- In concrete, it decreases efflorescence.

\section{Rice Husk Ash}

- $\quad$ Rice husks are the tough protective coverings that protect rice grains. Rice hulls may be used as a construction material. Rice hulls are found in the rice chaff. The rice husk contains $75 \%$ volatile organic matter, and the rest is inorganic.

- Amorphous silica accounts for 85 to $90 \%$ of the amorphous silica in rice husk. Materials containing silica and alumina, known as pozzolana, have their binding property. A wide range of siliceous or aluminous products, including ash from various agricultural and industrial wastes, maybe pozzolanic.

- As compared to OPC concrete, it has a stronger bond.

- Concrete permeability decreases chloride diffusion, and chloride permeation reduces by $30 \%$.

- RHA contributes to improved chemical resistance.

\section{Test Results}

- For 28 days, the compressive strength of conventional Concrete of M30 grade was found to be 40.47. The compressive strength of ternary blended concrete (5 percent $\mathrm{FA}+5$ percent $\mathrm{SF}$ ) has been measured at $45.76 \mathrm{~N} / \mathrm{mm} 2$.

- As the percentage of FA and SF increases, the strength varies, and when it reaches the portion of the cap, the strength decreases. For ternary blended concrete (5 percent $\mathrm{FA}+5$ percent SF) of M30 grade concrete, the split tensile strength value was $2.5 \mathrm{~N} / \mathrm{mm} 2$ after 28 days.

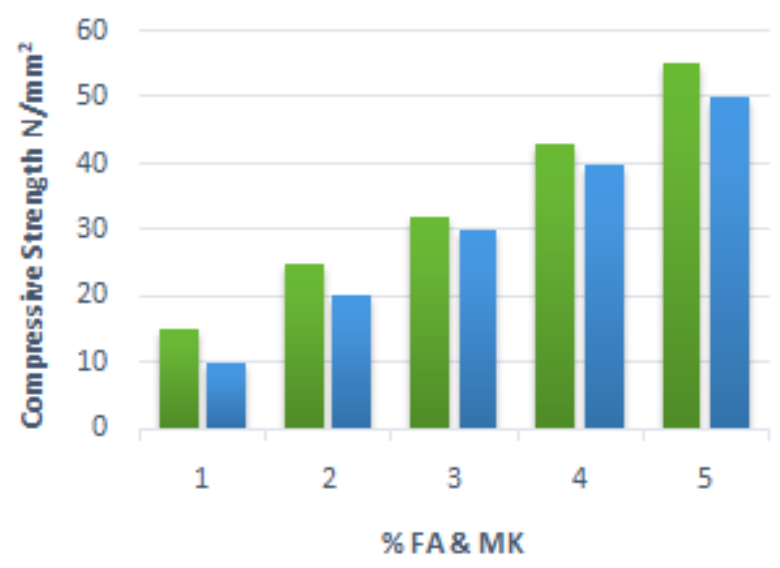

\section{CONCLUSION}

- The minor compressive strength is gained at $40 \%$ and 50\% combinations, respectively, resulting in a decrease in bond strength. The fineness of FA and Micro Silica particles is affected by this. The compressive intensity as the percentage of GGBS increases, the intensity decreases.

- The strength gained by combining and the highest strength gained of all mixes for M30 grade is 28 days. As the percentage of Metakaolin increases, the other combinations achieve the most negligible strength value. The mixture yielded the maximum strength of $43.58 \mathrm{~N} / \mathrm{mm} 2$, while the different mixes yielded less strength for percentages ranging from $10 \%$ to $30 \%, 40 \%$, and $50 \%$.

- The split tensile strength varies and fluctuates as the percentages of SF are increased. At 28 days, the split tensile strength values for ternary blended concrete of M30 grade concrete. The split tensile values for ternary mixed concrete with a mixture of mixes the split tensile strength is combined.

- The split tensile strength is the strongest of all the mixes. As the RHA was raised, the material's tensile strength decreased. The C-S-H gel develops from SEM observations of the mix of FA+SF, mineral elements, and reaction. The strength and microstructural behavior of concrete are improved by substituting cost-effective materials for concrete ingredients. According to SEM observations, the large crystals are tightly packed and coated with $\mathrm{Ca}(\mathrm{OH})_{2}$. The structure is tightened, with large platelets and small clusters, as well as lower matrix porosity.

\section{REFERENCES}

1. Gopu Anil, Gomasa Ramesh, and Dr. Annamalai Rangasamy Prakash, "An Experimental Study Investigation on Self Compacting Concrete and Strength Properties by using Fiber Reinforcement", International Journal for Modern Trends in Science and Technology, Vol. 07, Issue 02, February 2021, pp.-93-96, DOI: 10.46501/IJMTST0702016.

2. Sriramoju Sravani, Gomasa Ramesh and Dr. G. Dinesh Kumar, "Study on Percentage Replacement of Cement by Glass powder for M20 Grade Concrete", International Journal for Modern Trends in Science and Technology, Vol. 07, Issue 02, February 2021, pp: 129132, DOI:10.46501/IJMTST0702022.

3. Bandi Pooja, Gomasa Ramesh and Dr. G. Dinesh Kumar, "Experimental Study on Mechanical Properties of Geopolymer Concrete by using Fly Ash and RHA", International Journal for Modern Trends in Science and Technology, Vol. 07, Issue 02, February 2021, pp.-50-55, DOI:10.46501/IJMTST0702008.

4. Vangala Saipriya, Gomasa Ramesh and Dr.G. Dinesh Kumar, "An Experimental Observe of Replacing Conventional Coarse Aggregate with Electronic Waste for M45 Grade concrete Using Natural Sand", International Journal for Modern Trends in Science and Technology, Vol. 07, Issue 03, March 2021, pp.: 115-118, DOI:10.46501/IJMTST0703020. [CrossRef]

5. Palakurthi Manoj Kumar, Gomasa Ramesh and Dr. Annamalai Rangasamy Prakash, "Evaluation of Different Tests and their Comparisons by Combining Cement with Various Binders", International Journal for Modern Trends in Science and Technology, Vol. 07, Issue 03, March 2021, pp.: 119-122, DOI: 10.46501/IJMTST0703021.

6. Bonagani Vamshi Krishna, Gomasa Ramesh and Dr. Annamalai Rangasamy Prakash, "Effect of Geo-Activator on Strength and Durability Properties of Geopolymer Concrete", International Journal for Modern Trends in Science and Technology, Vol. 07, Issue 03, March 2021, pp.: 123-126, DOI: 10.46501/IJMTST0703022.

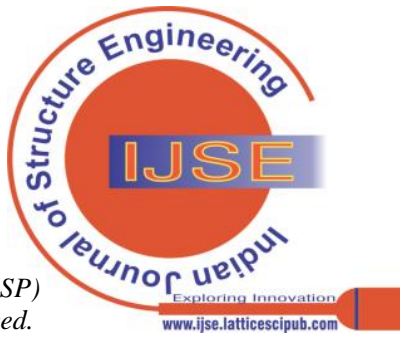


7. Gomasa Ramesh, Dharna Ramya, Mandala Sheshu Kumar; "Health Monitoring of Structures by Using Non-Destructive Testing Methods", International Journal of Advances in Engineering and Management (IJAEM) Volume 2, Issue 2, pp: 652-654, DOI: 10.35629/5252-45122323, ISSN:2395-5252, ISO 9001: 2008 Certified Journal.

8. Gomasa Ramesh, Doddipati Srinath, Mandala Sheshu Kumar; "Earthquake Resistant of RCC Structures" Published in International Journal of Trend in Scientific Research and Development (ijtsrd), ISSN: 2456-6470, Volume-4, Issue-5, August 2020, pp.808-811.

9. Gomasa Ramesh, Doddipati Srinath, Mandala Sheshu Kumar, "Importance of Dynamic Analysis for RCC Structures", International Journal for Modern Trends in Science and Technology, 6(8): 271276, 2020, DOI: 10.46501/IJMTST060844. [CrossRef]

10. Gomasa Ramesh, Mandala Sheshu Kumar and Palakurthi Manoj Kumar, "Introduction to Finite Element Methods in Engineering", International Journal for Modern Trends in Science and Technology, 6(9): 167-174, 2020, DOI: 10.46501/IJMTST060926. [CrossRef]

11. Gomasa Ramesh, Dr. Annamalai Rangasamy Prakash, "Repair, Rehabilitation and Retrofitting of Reinforced Concrete Structures", Special Issue 2021, International Journal of Engineering Research \& Technology (IJERT) ISSN: 2278-0181 Published by, www.ijert.org NCACE - 2020 Conference Proceedings.

12. Dharna Ramya, Gomasa Ramesh and Dr. Annamalai Rangasamy Prakash, "Shear Behavior of Hybrid Fiber Reinforced Concrete", International Journal for Modern Trends in Science and Technology, Vol. 07, Issue 02, February 2021, pp.-79-82, DOI: 10.46501/IJMTST0702013.

13. Gomasa Ramesh, "Study on Mechanical Properties of Polyurethane Foam Concrete", Indian Journal of Structure Engineering (IJSE) Volume-1 Issue-1, May 2021, pp:1-3, DOI:10.35940/ijse.B8005.051121. [CrossRef]

14. Ramesh 2021 et al., "Transparent Concrete: A Review", Indian Journal of Structure Engineering (IJSE) Volume-1 Issue-1, May 2021, pp:4-8, DOI:10.35940/ijse.B8005.051121. [CrossRef]

15. Ramesh 2021 et al., "Pervious Concrete: A Review", Indian Journal of Structure Engineering (IJSE) Volume-1 Issue-1, May 2021, pp:48, DOI:10.35940/ijse.B8005.051121. [CrossRef]

16. Mandala Sheshu Kumar, Gomasa Ramesh , Dr. Annamalai Rangasamy Prakash, "Investigation of the Strength and Durability of Partially Replacing Cement with GGBS and Alccofine", International Journal of Innovative Research in Science, Engineering and Technology (IJIRSET), Volume 10, Issue 4, April 2021, pp:3789-3795, DOI:10.15680/IJIRSET.2021.1004137.

17. Gomasa Ramesh, Maddela Jyothi Kiran, Palakurthi Manoj Kumar, "A Study on Geopolymer Concrete", International Journal of Innovative Research in Science, Engineering and Technology (IJIRSET), Volume10, Issue 4, April 2021, pp:3818-3824, DOI:10.15680/IJIRSET.2021.1004142.

18. Ramesh 2021 et al., "Geopolymer Concrete: A Review", Indian Journal of Structure Engineering (IJSE) Volume-1 Issue-2, November 2021, PP:5-8， DOI:10.35940/ijse.A1302.111221. [CrossRef]

19. Ramesh 2021 et al., "Self-Compacting Concrete: A Review", Indian Journal of Structure Engineering (IJSE) Volume-1 Issue-2, November 2021, PP:9-12， DOI:10.35940/ijse.A1303.111221. [CrossRef]

20. Gomasa Ramesh, Gopu Anil, Doddipati Srinath, "A Study on Underwater Concrete Structures", International Journal of Innovative Research in Science, Engineering and Technology (IJIRSET), Volume 10, Issue 4, April 2021, DOI:10.15680/IJIRSET.2021.1004145.

21. Gomasa Ramesh, D Srinath, "Repair, rehabilitation and retrofitting of reinforced concrete structures by using non-destructive testing methods," March 2021, Materials Today: Proceedings, DOI: 10.1016/j.matpr.2021.02.778 [CrossRef]

22. D Srinath, G Ramesh, "Mechanical properties of sustainable concrete by using RHA and hydrated lime," March 2021, Materials Today: Proceedings, DOI: 10.1016/j.matpr.2021.02.785 [CrossRef]

\section{AUTHORS PROFILE}

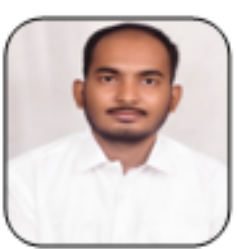

Mr. Gomasa Ramesh, B. Tech Civil Engineering, M. Tech Structural Engineering, Vaagdevi College of Engineering, Warangal, 506005, Telangana, India. Presented and participated in various International conferences and National Conferences and received Best Paper Awards for some Papers and received Best Young Researcher Award for 2020. Published more than
20 Research Papers in International Peer-Reviewed UGC Journals. Member of various Professional Bodies American Society of Civil Engineers, Structural Engineering Institute, Institute of Structural Engineering, American Concrete Institute and American Society of Testing Materials etc.

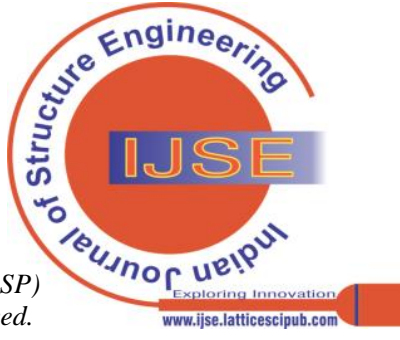

